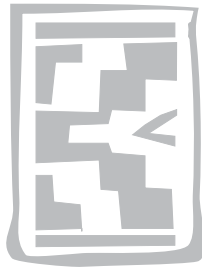

\title{
Helminths of guineafowls in Limpopo Province, South Africa
}

\author{
K. JUNKER and J. BOOMKER* \\ Department of Veterinary Tropical Diseases, Faculty of Veterinary Science, University of Pretoria, Private \\ Bag X04, Onderstepoort, O110 South Africa
}

\begin{abstract}
JUNKER, K. \& BOOMKER, J. 2007. Helminths of guineafowls in Limpopo Province, South Africa. Onderstepoort Journal of Veterinary Research, 74:265-280

Between July 2005 and November 2006 the gastro-intestinal helminths of 15 Helmeted guineafowls and a single Crested guineafowl from Musina, Limpopo Province were examined, and in July and August 2005 helminths were collected from five Helmeted guineafowls from Mokopane in the same province. The acanthocephalan Mediorhynchus gallinarum, the cestodes Abuladzugnia gutterae, Davainea nana, Hymenolepis cantaniana, Numidella numida, Octopetalum numida, Ortleppolepis multiuncinata, Porogynia paronai, Raillietina angusta, Raillietina pintneri, Raillietina steinhardti and Raillietina sp. and the nematodes Ascaridia numidae, Cyrnea parroti, Gongylonema congolense, Hadjelia truncata, Sicarius caudatus, Subulura dentigera, Subulura suctoria, Subulura sp., Tetrameres numida and an unidentified subulurid were recovered. A single trematode species, Dicrocoelium macrostomum, was present in the liver. Mediorhynchus gallinarum, $A$. gutterae, $O$. multiuncinata, $H$. truncata and $S$. caudatus are recorded for the first time from Helmeted guineafowls, as well as from South Africa. South Africa is a new geographic record for $D$. macrostomum, $G$. congolense and $D$. nana. Subulura suctoria, $G$. congolense and $H$. truncata from the Crested guineafowl constitute new hostparasite associations.
\end{abstract}

Keywords: Acanthocephalans, cestodes, guineafowls, Guttera edouardi, nematodes, Numida meleagris, trematodes

\section{INTRODUCTION}

Helmeted guineafowls, Numidameleagris(Linnaeus, 1758), are distributed throughout most of South Africa and almost the entire African continent (Del Hoyo, Elliot \& Sargatal 1994). Studies to elucidate the helminth fauna of these hosts in South Africa have been undertaken by Saayman (1966), Crowe (1977) and Verster \& Ptasinska-Kloryga (1987), but were restricted to the Eastern Cape, the Northern Cape and Gauteng Provinces.

* Author to whom correspondence is to be directed. E-mail: joop.boomker@up.ac.za

Accepted for publication 13 April 2007-Editor
Although relatively wide-spread in Africa, Crested guineafowls, Guttera edouardi (Hartlaub, 1867), are scarce and have a limited distribution within South Africa. They occur in the Limpopo, North West, Mpumalanga and KwaZulu-Natal Provinces and are listed as rare or accidental in Gauteng Province (Hockey, Dean \& Ryan 2005; Lepage 2007). To date our knowledge concerning their helminth fauna is virtually non-existent.

Ortlepp $(1937,1938 a, b, 1963)$ reported on the cestode and nematode parasites of guineafowls of southern Africa present in the National Collection of Animal Helminths, formerly known as the Onderstepoort Helminthological Collection, or material made 
available to him by various collectors. He described several new species of cestodes and nematodes and added numerous parasites to the host-parasite list of guineafowls in South Africa. His reseach, however, was of a taxonomic nature and the material at his disposal represented incidental findings rather than complete collections.

In this paper we present data obtained from 16 birds, including a single Crested guineafowl, at Musina, Limpopo Province, and from five Helmeted guineafowls at Mokopane, Limpopo Province, South Africa.

\section{MATERIAL AND METHODS}

In July and August 2005 a total of five Helmeted guineafowls were sampled in the vicinity of Mokopane (Potgietersrus), Limpopo Province. A complete helminth recovery was not possible, but some of the worms present in the small intestine of three of the birds, the complete caeca of one of them and part of the intestinal and caecal contents of another were collected and fixed separately in $70 \%$ ethanol.

In July 2005 and in May, July and November 2006, three, five, three and four Helmeted guineafowls (eight males and seven females) were collected on a farm approximately $60 \mathrm{~km}$ west of Musina (Messina), Limpopo Province ( $22^{\circ} 22^{\prime} \mathrm{S}, 2^{\circ} 30^{\prime} \mathrm{E}$, Altitude $700-800 \mathrm{~m}$ ). The vegetation type in the study area is classified as Mopani veld (Acocks 1988).

The birds were aged according to the criteria established by Siegfried (1966) and in total ten adults and five juveniles were collected. The juveniles were between six and ten months old (Siegfried 1966). In November 2006 a single adult female Crested guineafowl, found moribund in a wire snare, was made available to us for examination.

The carcasses of the birds were opened according to standard techniques for necropsies of chickens, and the viscera removed. The trachea was opened and macroscopically examined for helminths.

The crop, proventriculus, gizzard, small intestine and caecum/colon were separated and individually washed over a $150 \mu \mathrm{m}$ sieve. The livers of nine Helmeted guineafowls and the single Crested guineafowl were sliced into $5 \mathrm{~mm}$ wide sections and incubated in phosphate-buffered saline at $40^{\circ} \mathrm{C}$ for 30 $\min$. Subsequently, the slices together with the saline were washed over a $150 \mu \mathrm{m}$ sieve. The gastrointestinal and liver residues left on the sieves, as well as the organs themselves were fixed separately in $70 \%$ ethanol and transported to the laboratory at Onderstepoort. Each sample was examined under a stereoscopic microscope and the helminths removed.

Cestodes were stained in haematoxylin and mounted in Canada balsam or mounted and cleared in Hoyer's medium. Acanthocephalans were cleared in Hoyer's medium and studied as temporary mounts in the same medium. All nematodes were cleared in lactophenol for identification.

The ecological terms are used in accordance with the definitions of Margolis, Esch, Holmes, Kuris \& Schad (1982).

\section{RESULTS}

All the guineafowls were infected and all were concurrently parasitized by acanthocephalans, cestodes and nematodes.

Data on the prevalence, intensity and habitat preference of the parasites from the Helmeted guineafowls in Musina are presented in Tables 1 and 2. Five of the nine hosts $(55.6 \%)$, whose livers were examined, harboured Dicrocoelium macrostomum, the intensity of infection ranging from 8 to 182 flukes. In addition, the livers of three of the nine birds yielded five, 11 and five young specimens of Porogynia paronai. These had the typical three circles of large hammershaped rostellar hooks and small, unarmed suckers. No differential development could be seen in any of the proglottids of the short strobilae which ranged from 2.3 to $3.8 \mathrm{~mm}(n=5)$ in length. The scolices were 689-746 $\mu \mathrm{m}$ wide and the rostella were 261$329 \mu \mathrm{m}$ wide.

Birds from Mokopane yielded the nematodes SubuIura suctoria, Subulura dentigera and Ascaridia numidae and seven cestodes, namely Ortleppolepis multiuncinata, Porogynia paronai, Raillietina steinhardti, Raillietina pintneri, Raillietina sp., Numidella numida and Octopetalum numida.

Subulura dentigera and S. suctoria were co-specific in the two hosts from Mokopane. One of these harboured a total of 579 nematodes consisting of 142 male and 159 female S. suctoria, 134 male and 126 female $S$. dentigera and 18 immature Suctoria spp. These nematodes were suspended freely in the contents of the posterior saccate part of the caeca, virtually occupying the entire lumen (Fig. 2D).

Eight of the 15 helmeted guineafowls from Musina harboured $S$. dentigera and $S$. suctoria concurrently, and in all these hosts $S$. suctoria by far outnumbered 


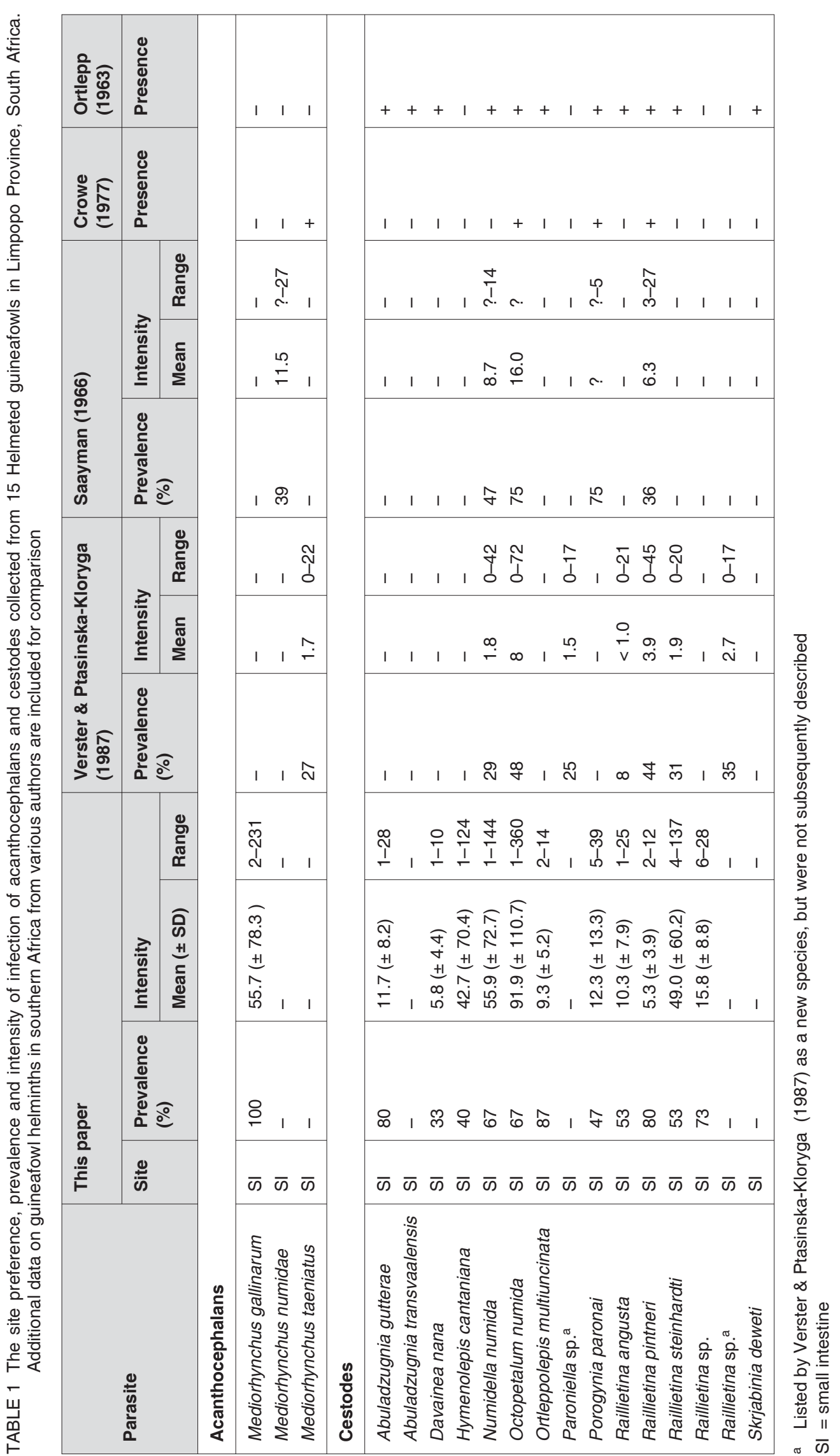




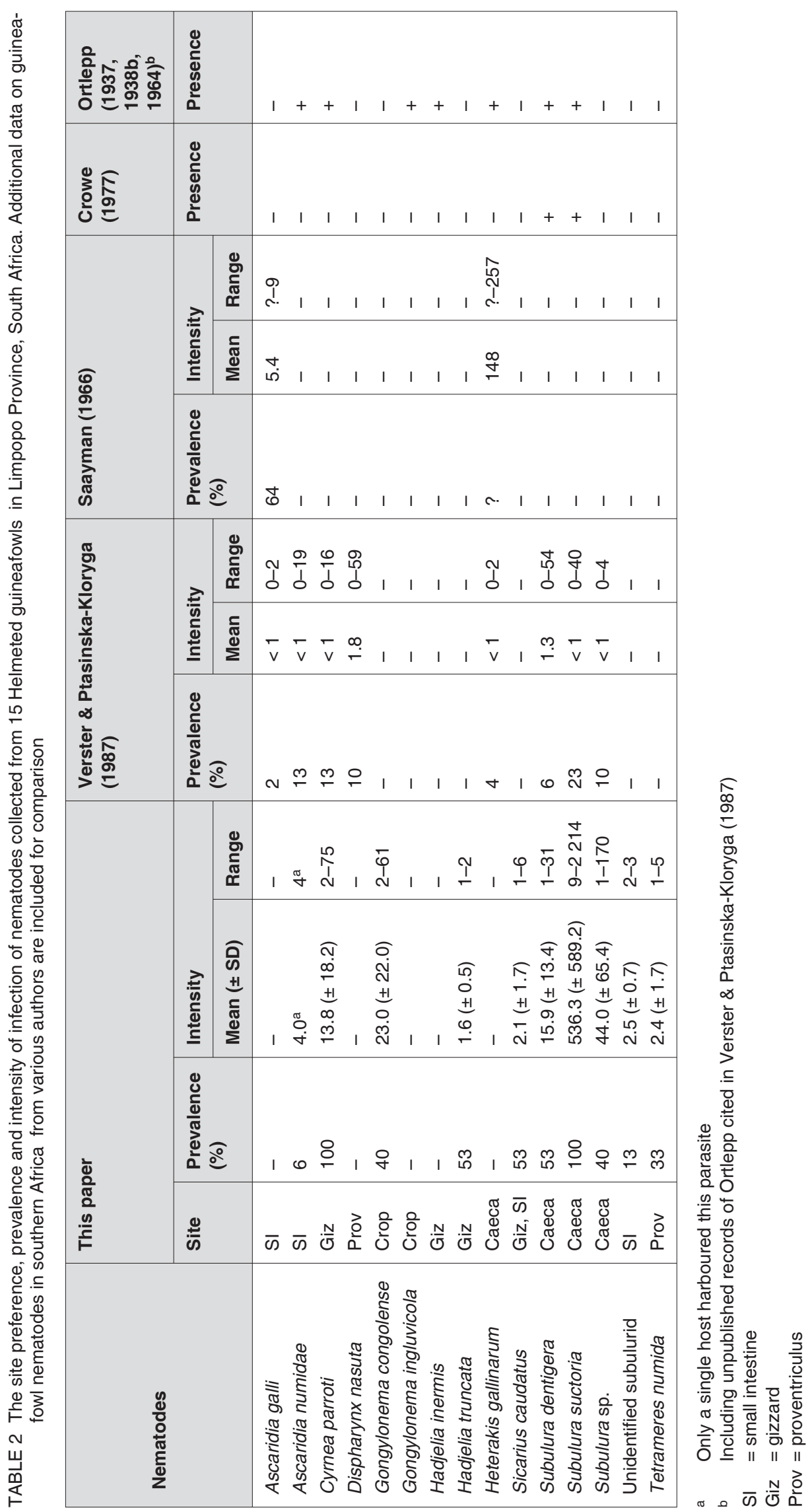


S. dentigera, the ratio ranging from 4.5:1 to $53: 1$. In the remaining hosts only $S$. suctoria was present (Fig. 2E, F).

The Crested guineafowl harboured a single acanthocephalan species, Mediorhynchus gallinarum ( $n$ $=48$ ), five species of cestodes, namely Abuladzugnia gutterae $(n=1), N$. numida $(n=114)$, O. numida ( $n$ $=57)$, O. multiuncinata $(n=1)$ and $P$. paronai $(n=$ 52 ), as well as three species of nematodes, S. suctoria $(n=260)$, Gongylonema congolense $(n=56)$ and Hadjelia truncata $(n=2)$, representing a total of 591 helminths.

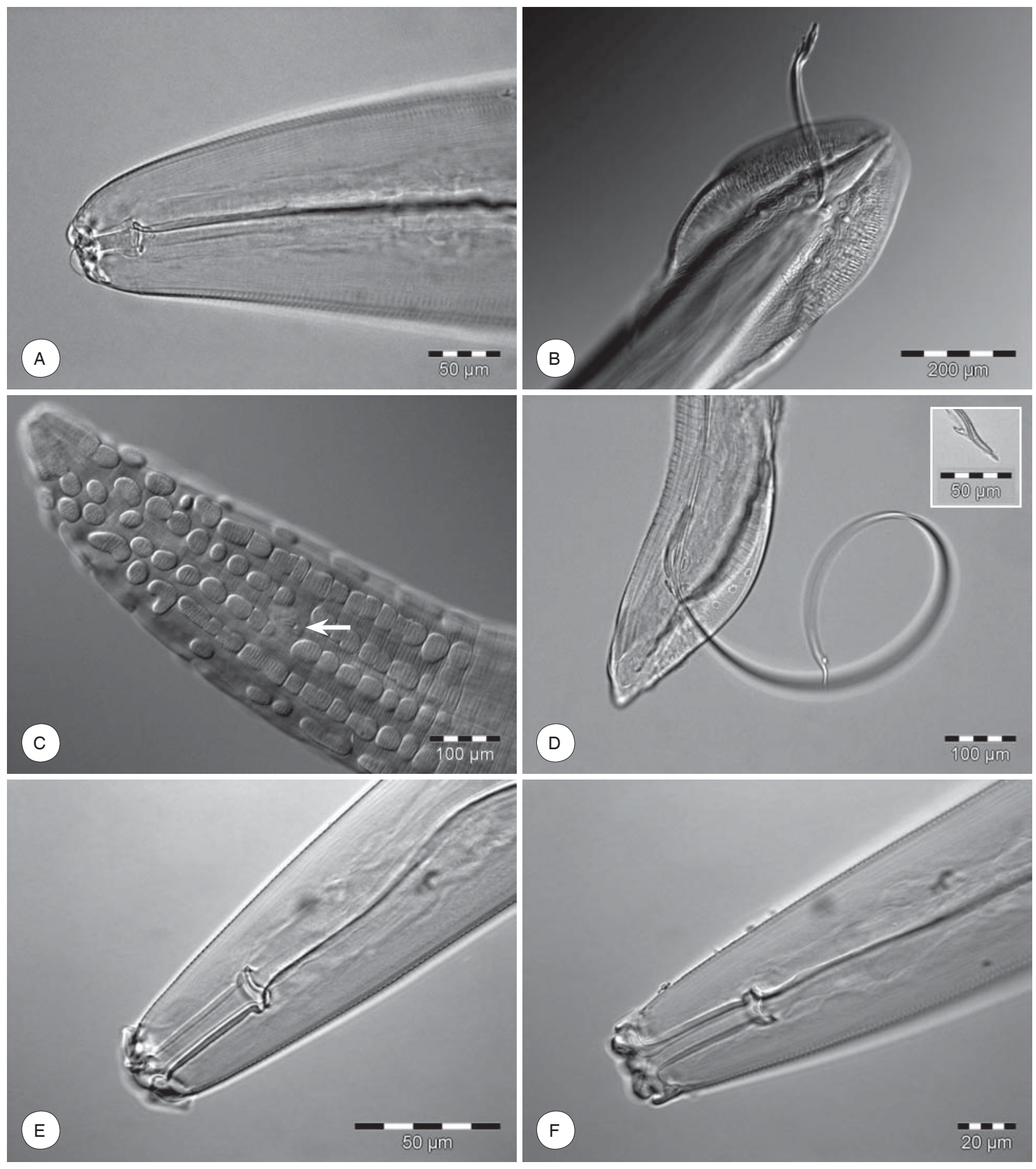

FIG. 1 A, B. Cyrnea parroti male. A. Anterior end. B. Posterior end. C, D. Gongylonema congolense. C. Anterior extremity of female, ventral view. The arrow points to the excretory pore. D. Posterior extremity of male. The inset illustrates the barbed tip of the long spicule. E, F. Hadjelia truncata male. E. Ventral view of anterior extremity. F. Lateral view of anterior extremity 
Our finding of M. gallinarum, A. gutterae, H. multiuncinata, $H$. truncata and Sicarius caudatus in Helmeted guineafowls in South Africa constitutes new host associations, as well as new geographic records for these parasites. Dicrocoelium macrostomum, G. congolense and Davainea nana are recorded in
South Africa for the first time, and the Crested guineafowl is a new host for the nematodes $S$. suctoria, $G$. congolense and $H$. truncata.

Despite the generally high helminth burdens, the Helmeted guineafowls were in good physical condi-
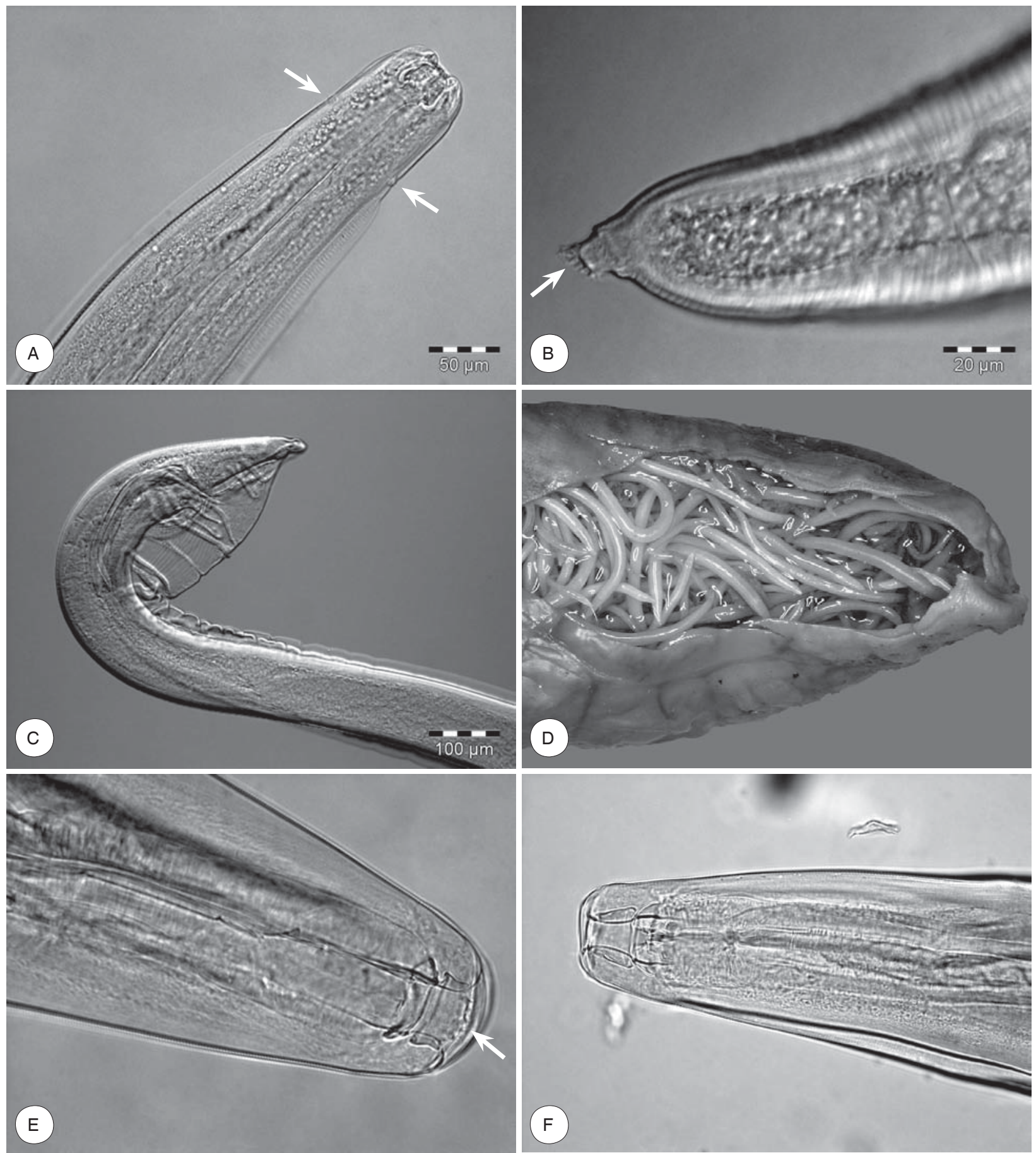

FIG. 2 A, B, C. Sicarius caudatus. A. Anterior extremity of male. The deirids are marked by arrows. B. Posterior extremity of female. Note the finger-like protruberances (arrow) at the tip of the tail. C. Posterior extremity of male. D. Distal part of guineafowl caecum filled with Subulura spp. E. Subulura dentigera female, anterior part. The arrow indicates the cuticular denticles as described by Ortlepp (1937); x 400. F. Subulura suctoria female, anterior part; x 400 
tion and no obvious lesions were associated with the presence of helminths. The crop mucosa of a single bird from Musina had an inflamed appearance. This, however, did not seem to be related to G. congolense living in shallow tunnels under the crop lining, but rather to the presence of numerous thorny seeds of Tribulus terrestris.

\section{TAXONOMIC REMARKS}

Cyrnea parroti Seurat, 1917 (Table 3; Fig. 1A, B)

Ortlepp (1938b) described Habronema numidae from Helmeted guineafowls in Malawi, South Africa and Swaziland. This nematode has subsequently been included in the genus Cyrnea Seurat, 1914, but it is still listed under its original name in Yamaguti (1961) as well as in Verster \& Ptasinska-Kloryga (1987).

In his work on the Habronematinae, Chabaud (1958) divided the genus Cyrnea into two subgenera, Procyrnea Chabaud, 1958 and Cyrnea Chabaud, 1958, which he later raised to genus level (Chabaud 1975). Following an in-depth study of the cephalic structures, he synonymized Cyrnea (Cyrnea) numidae (Ortlepp, 1938) with Cyrnea (Cyrnea) parroti Seurat, 1917 (Chabaud 1958).

Specimens from our hosts mounted en face show the same arrangement of submedian lobes and simple lips as illustrated for C. parroti by Chabaud (1958) and otherwise conform well with the description and measurements supplied by Ortlepp (1938b) for $C$. numidae. The range of measurements in our specimens was, however, generally wider than that provided by the latter author (Table 3). Ortlepp (1938b) himself stated that his new species most closely resembled Cyrnea eurycerca and $C$. parroti and that the arrangement of the caudal papillae in the males as well as the spicules were very similar.

\section{Gongylonema congolense Fain, 1955 (Table 4;} Fig. 1C, D)

This parasite was first described by Fain (1955a) from domestic chickens, a single duck, Cairina moschata domestica and from $N$. meleagris from the Democratic Republic of the Congo and Rwanda. Subsequently it has been recorded from $N$. meleagris in Burundi, Nigeria, Ethiopia, Ghana and Burkina Faso (Fain \& Thienpont 1958; Fabiyi 1972; Graber 1976; Hodasi 1976; Vercruysse, Harris, Bray, Nagalo, Pangui \& Gibson 1985).

One of the main morphological characteristics of this species is the hook situated at a distance of about
$50 \mu \mathrm{m}$ from the distal tip of the left spicule (Fain 1955a) (Fig. 1D). The hook itself carries three fine barbs. In our specimens the barbed hook of the tip of the left spicule was often difficult to see, but in specimens where the distance could be determined it varied from 31 to $46 \mu \mathrm{m}$.

It is not always easy to judge whether the left spicule is intact or damaged, which could lead to measuring errors. There are, however, sufficient other characteristics, such as the gubernaculum, the extent and arrangement of the cuticular plaques (Fig. $1 \mathrm{C})$, as well as the length of the right spicule to differentiate $G$. congolense from other species utilizing avian hosts (Fain 1955a).

While our specimens fit in well with Fain's (1955a, b) description of $G$. congolense, we have not been able to confirm that the excretory pore opens on a transversally elongated plaque as was described by him. In our specimens it would seem that the two median ventral longitudinal rows of plaques are interrupted, leaving a plaque-free zone immediately anterior and posterior to the excretory pore (Fig. 1C).

Measurements of our specimens and those of Fain (1955a) taken from guineafowl hosts are presented in Table 4. These indicate that there is little geographic variation in the morphology of G. congolense from the same host species.

\section{Hadjelia truncata (Creplin, 1825) (Table 5; Fig. 1E, F)}

The most obvious differences between $H$. truncata and sympatric specimens of $C$. parroti are the position of the vulva and the winged appearance of the lips of $H$. truncata in ventral view (Fig. 1E, F). In $H$. truncata the vulva is distinctly anterior and positioned in front of the posterior end of the oesophagus. These characteristics are in accordance with the generic diagnosis of Hadjelia provided by Yamaguti (1961).

Measurements of the specimens from the guineafowls fall well within the range of measurements provided by Ortlepp (1964) for Hadjelia inermis (Gedoelst, 1919) (Table 5). Hadjelia inermis had been synonymized with $H$. truncata by Chabaud \& Campana (1950), and Ortlepp (1964) commented on this, but chose to retain the former species. He lists his own measurements for $H$. inermis collected from Red- and Yellow-billed hornbills from South Africa, together with measurements for $H$. inermis taken from Gedoelst (1919) and for $H$. inermis and $H$. truncata as provided by Cram (1927, cited by Ortlepp 


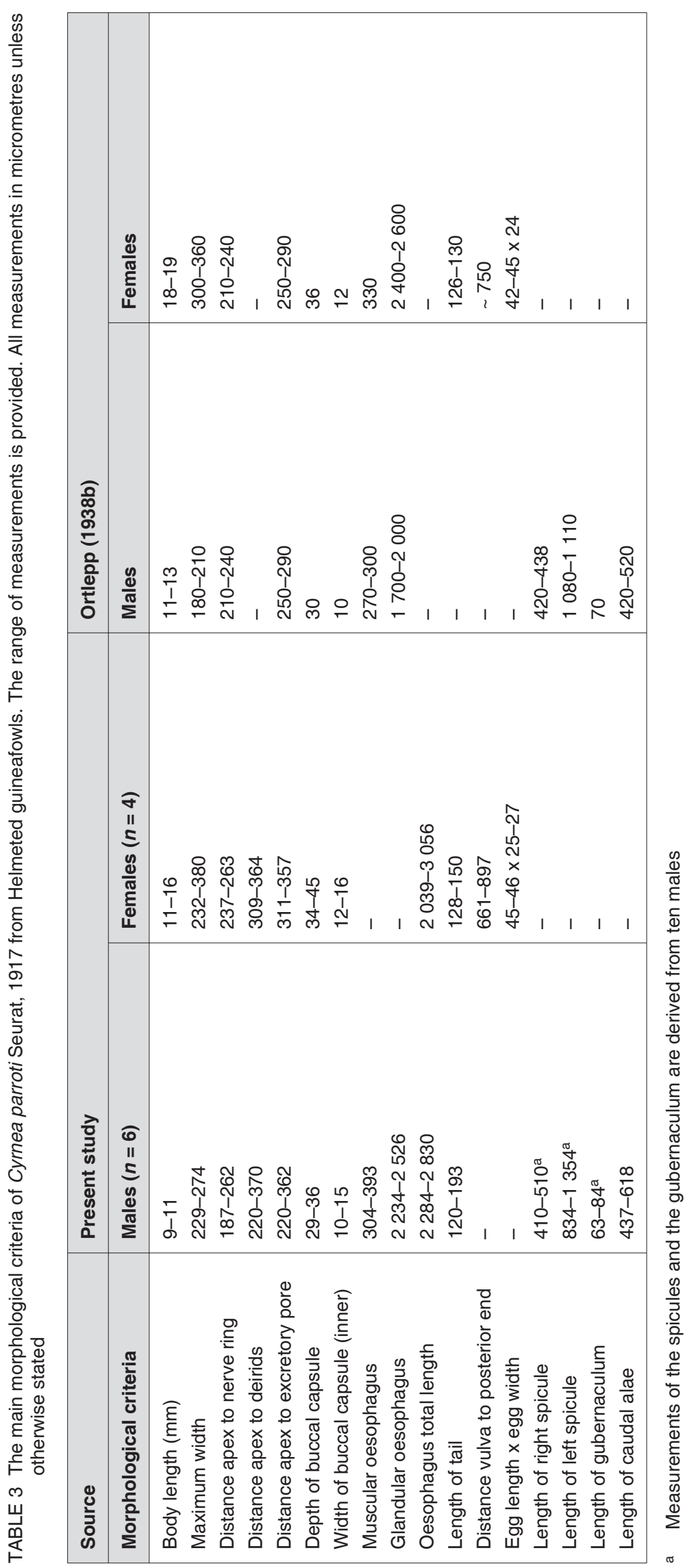




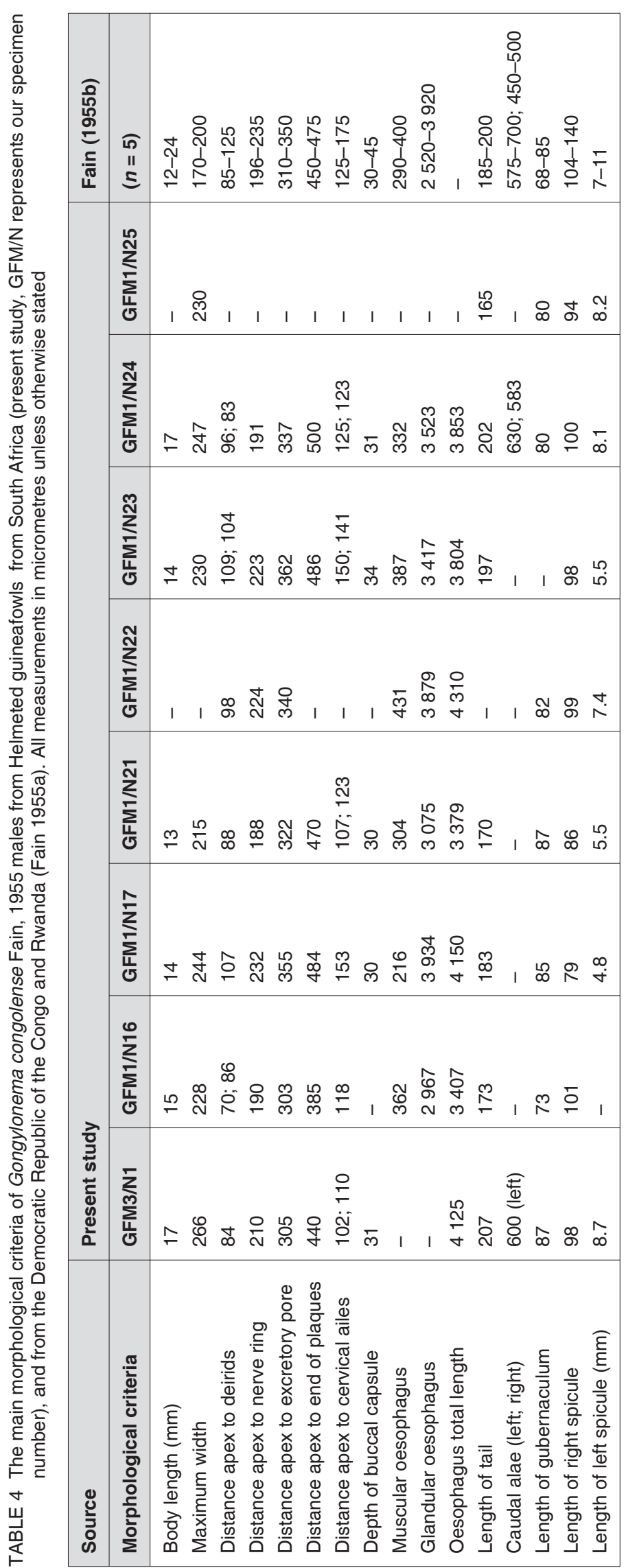




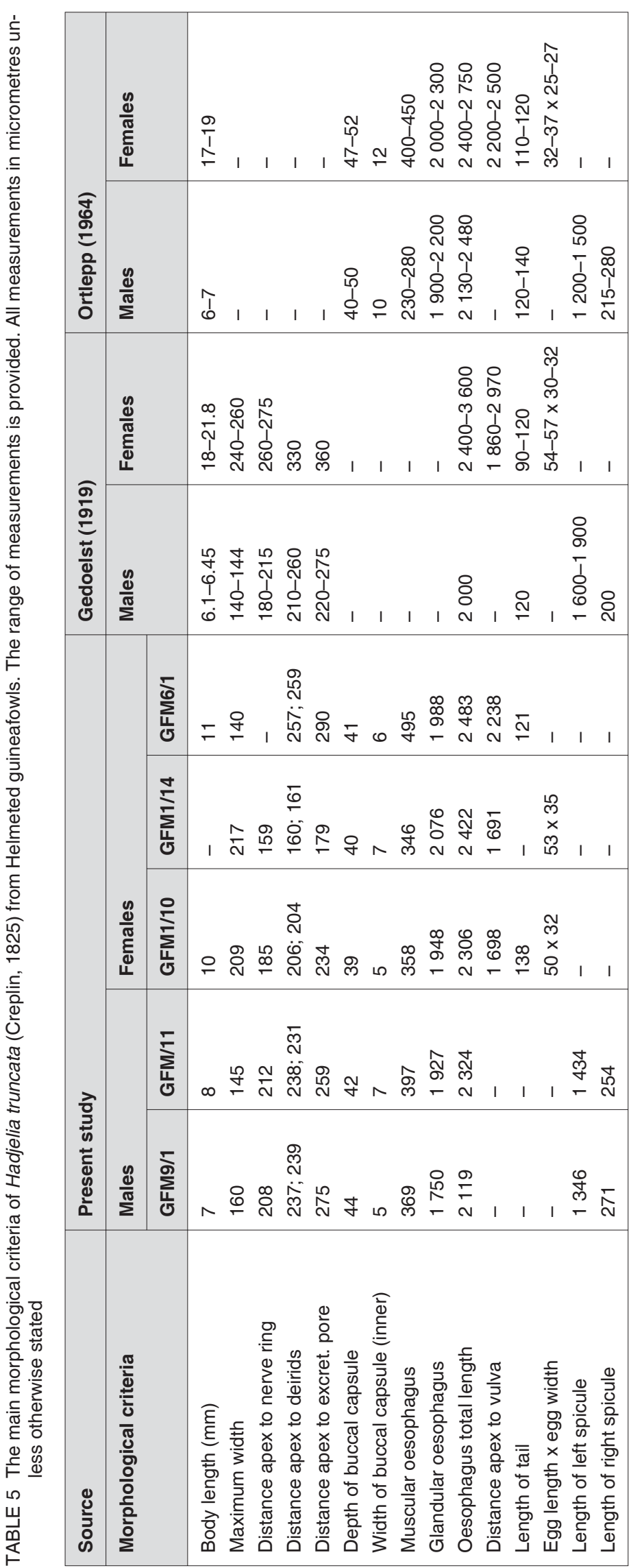


1964) (Table 5). As we have not been able to examine the type specimens of either species, we have chosen to adopt the conclusion of the in-depth morphological study of Chabaud \& Campana (1950).

The single complete specimen in our collection appears slightly shorter than previously described ones. The depth of the buccal cavity of our specimens corresponds with the lower range of the pharynx sizes provided by Ortlepp (1964) and all three authors he quoted.

The oesophagus length is relatively uniform in all the sources quoted by Ortlepp (1964). In our specimens the total length of the oesophagus only reached 2.1 and $1.9 \mathrm{~mm}$ which, considering that these specimens are short, does not seem extraordinary. The egg size is very similar to that of $H$. inermis as recorded by Gedoelst (1919) and Cram (1927, cited by Ortlepp 1964), but larger than given by Ortlepp (1964). Ortlepp (1964) pointed out that this was the only noteworthy difference between his specimens and those described by Gedoelst (1919).

According to Chabaud (1958) the genus Hadjelia has been described from numerous birds, especially Coraciiformes, from Europe, Asia and Africa. Data pertaining to African hosts mainly list Bucerotiformes (Ortlepp 1964) and we are aware of only one reference to Hadjelia from galliform birds, namely $\mathrm{Had}$ jelia Ihuillieri Seurat, 1916 from Alectoris barbara (= Caccabis petrosa from Algeria in Seurat 1916). Incidentally, Chabaud (1958) speculated that the latter species might be identical with $H$. truncata, but thought that the characteristics of the single known female specimen of $H$. Ihuillieri were not sufficient to draw a final conclusion.

\section{Sicarius caudatus Quentin \& Wertheim, 1975 (Table 6; Fig. 2A, B, C)}

Four species of the genus Sicarius are known from avian hosts, namely Sicarius dipterum (Popova, 1927), Sicarius hoopoe Sharma, 1971, Sicarius caudatus Quentin \& Wertheim, 1975 and Sicarius renatae Cancrini, Balbo \& lori, 1991. The left spicule of $S$. dipterum is distinctly longer $(660-670 \mu \mathrm{m})$ than that of our specimens, whereas the subequal spicules of $S$. hoopoe are 440-560 and 470-600 $\mu \mathrm{m}$ in length (Cancrini, Balbo \& lori 1991). Our specimens best fit the description of $S$. caudatus, as they have six pairs of caudal papillae as opposed to the eight pairs of S. renatae (Cancrini et al. 1991).

According to Quentin \& Wertheim (1975) the deirids in $S$. caudatus are situated at the origin of the lateral alae. In some of our specimens, we have observed the same arrangement, but in one male and one female the right and left deirids emerge 11 and $27 \mu \mathrm{m}$, and 17 and $37 \mu \mathrm{m}$ anterior to the origin of the alae (Fig. 2A). We have too little material to comment on the significance of this observation.

Quentin \& Wertheim (1975) describe the cuticular processes in the tail of $S$. caudatus as atrophied, the tail consisting merely of a smooth stump, which at best has rugged edges. Our specimens possess about seven distinct, albeit short, cuticular extensions similar to those illustrated by Cancrini et al. (1991) for S. renatae (Fig. 2B). Despite these differences we have allocated our specimens to $S$. caudatus. Apart from the original description and their inclusion in some taxonomic reviews (Chabaud 1958; Ali 1961), we have not found any other references to $S$. caudatus in the literature. The measurements of the specimens collected during this study are included in Table 6.

\section{DISCUSSION}

Despite the fact that various studies on the helminths of guineafowls in South Africa have been conducted, direct comparisons between the results of these studies are not always possible, as they had different objectives. Ortlepp (1937, 1938a, b, 1963) studied the helminths of all the organs and the entire alimentary canal, but his work was of a taxonomic nature, based on incidental findings, and presented no epidemiological data. Crowe (1977) listed the helminth species recovered from the small intestine, caeca and rectum of guineafowls, but in his subsequent analysis grouped them as acanthocephalans, cestodes and nematodes respectively. The two studies providing data on the prevalence and intensity of the helminths are those of Saayman (1966) and Verster \& Ptasinska-Kloryga (1987). However, Saayman (1966) only examined the intestinal tract and Verster \& Ptasinska-Kloryga (1987) collected helminths from the gizzard, intestine and caeca. Thus, their data on species richness would not reflect worms located in e.g. the crop or proventriculus.

The study conducted on guineafowls in Burkina Faso by Vercruysse et al. (1985) lends itself best to comparison with ours, as they examined the complete alimentary tract, including the crop and proventriculus. Of the total of 13 helminth species collected by these authors, eight species coincide with species recovered from our hosts. If the single acanthocephalan present in the birds from Burkina Faso 
is taken into account, this number will increase by one. Vercruysse et al. (1985) record the acanthocephalan Mediorhynchus selengensis, which has been synonymized with $M$. gallinarum by Schmidt \& Kuntz (1977), and the nematodes Cyrnea parroti, $S$. suctoria, $G$. congolense and $A$. numidae, which are also recorded in this study. In addition to these species, Vercruysse et al. (1985) recorded the cestode Cotugnia digonopora and the nematodes Eucoleus annulatus, T. fissispina and Dispharynx spiralis.

\section{Nematodes}

\section{Cyrnea}

With the exception of $C$. parroti, helminths were recovered from their usual predilection sites. According to Anderson (1992) members of the genus Cyrnea occur in the proventriculus of birds and he records Cyrnea colini in the wall of the proventriculus near the gizzard of Bobwhite quails. We did not recover C. parroti from the proventriculus, but in all infected guineafowls the parasites were situated under the gizzard lining and could only be seen after the horny layer had been removed. There seemed, however, to be a preference for the proventricular-gizzard isthmus as described for Cyrnea neeli from wild turkeys in the south-eastern United States (Davidson, Hon \& Forrester 1977). Similarly, C. parroti recovered from Helmeted guineafowls in Burkina Fasso were also present in the gizzard (Vercuysse et al. 1985).

\section{Subulura}

The genus Subulura has a wide distribution in gallinaceaous birds on the African continent and records exist from Zimbabwe, Tanzania, Ghana, Nigeria and Somalia (Nicholls, Bailey, Gibbons, Jones \& Samour 1995; Nfor, Ajanusi, Agbede \& Esievo 1999; Poulsen, Permin, Hindsbo, Yelifari, Nansen \& Bloch 2000; Permin, Esmann, Hoj, Hove \& Mukaratirwa 2002; Magwisha, Kassuku, Kyvsgaard \& Permin 2002). However, the genus is not restricted to the African continent and, according to Yamaguti (1961) is a cosmopolitan species.

Ortlepp (1937) recovered S. suctoria in association with $S$. dentigera from guineafowls from various regions in South Africa and Swaziland and concluded that the two species had a wide distribution. Contrary to our findings, he found $S$. dentigera to be far more abundant than $S$. suctoria.

Verster \& Ptasinska-Kloryga (1987) collected helminths from 48 guineafowls in the vicinity of Pretoria.
Subulura suctoria was present in 11 and $S$. dentigera in three of the hosts examined. From these and our own results it is apparent that the two species, S. suctoria and $S$. dentigera often share the same habitat. It is difficult to judge from our data whether these two species are interactive and compete for the same resources. If so, $S$. suctoria would seem the stronger competitor as it consistently occurred in higher numbers than $S$. dentigera. However, the numbers of $S$. dentigera were not greater in hosts with relatively low burdens of $S$. suctoria, but rather the numbers of $S$. dentigera were low in these hosts as well. It is possible, that this association is similar to the major-minor species concept, as seen with Theladorsagia circumcincta and Theladorsagia davtiani in sheep and goats.

A literature study confirms the dominance of $S$. suctoria in guineafowls and Vercruysse et al. (1985) recorded a $100 \%$ prevalence of $S$. suctoria from 103 Helmeted guineafowls in Burkina Faso. In addition to being the most prevalent nematode, these authors also found $S$. suctoria to be one of the most numerous parasites (26-1071 worms per host). Subulura dentigera was not reported from these hosts.

\section{Ascaridia numidae}

Ascaridia numidae is another nematode commonly encountered in Helmeted guineafowls and has been recorded from various geographic localities in Africa. The prevalence and intensity of this parasite varies greatly from $98.1 \%$ with a range of intensity from 1 to 1452 in hosts in Burkina Faso (Vercruysse et al. 1985 ) and $86.7 \%$ with intensities ranging from 1 to 504 in birds in Ghana (Hodasi 1976) to a low prevalence of $13 \%$ with a maximum of 19 worms per host in South Africa (Verster \& Ptasinska-Kloryga 1987). In the present study $A$. numidae was present in a single host only.

\section{Gongylonema}

Both Hodasi (1976) and Vercruysse et al. (1985), record $G$. congolense from hosts they examined, with a prevalence of 48.9 and $73.8 \%$, respectively. This indicates that $G$. congolense not only forms a regular part of the helminth community of guineafowls in South Africa, but throughout the African continent. With the exception of Gongylonema ingluvicola allegedly recorded by Ortlepp ("1937, 1938, unpublished records" cited by Verster \& PtasinskaKloryga 1987), the absence of this genus in previous reports on helminths of guineafowls in South 
Africa, is most likely due to the fact that earlier authors did not examine the crop of the hosts in their studies.

\section{Tetrameres}

While Tetrameres numida was recovered in low numbers from the Musina guineafowls, none of the more commonly reported species of this genus was present in our material. A second species, which has been recorded from guineafowls and is also a common parasite of domestic chickens, is Tetrameres fissispina Diesing, 1861. Vercruysse et al. (1985) report a $48.5 \%$ prevalence and an intensity of infection ranging from 1 to 146 worms per host from $\mathrm{Hel}-$ meted guineafowls in Burkina Faso, and $23.3 \%$ of 126 Helmeted guineafowls in Nigeria were infected with $T$. fissispina (Fabiyi 1972). In Ghana the prevalence of infection in the same host was $8.9 \%$ with a mean worm burden of 2.8, ranging from one to eight. Young scavenging chickens in Ghana had a prevalence of $T$. fissispina of $58 \%$ (Poulsen et al. 2000).

We are aware of a single record of three females of $T$. fissispina from a single Helmeted guineafowl in South Africa (Le Roux 1926), and the same author reports a high percentage of infection (78\%) in 60 domestic chickens in the same country. The proventriculus of a single, heavily infected host contained a minimum of 150 females (Le Roux 1926).

A third species commonly infecting domestic chickens, namely Tetrameres americana, which had a 60 and $62 \%$ prevalence in adult chickens in Tanzania and Zimbabwe, respectively (Permin, Magwisha, Kassuku, Nansen, Bisgaard, Frandsen \& Gibbons 1997; Permin et al. 2002), has not yet been recorded from guineafowls.

From the literature cited above it would appear that the prevalence of the genus Tetrameres is slightly higher in domestic chickens than in Helmeted guineafowls. Since the data above concerning the domestic chickens above pertain to free-ranging or scavenging chickens, guineafowls and domestic fowls probably had an equal chance of exposure to the parasite. Whether the higher infection rates in chickens are a result of higher host densities or whether guineafowls are generally more resistant towards helminth infections remains speculation.

\section{Trematodes}

The literature contains few reports of trematodes from guineafowl hosts, but a number of trematodes have been listed as parasitizing not only the diges- tive tract and urogenital system, but also the respiratory system of domestic fowls (Soulsby 1968). To our knowledge the only published records of trematodes from the liver of guineafowls are those of $D$. macrostomum, that occurs in the gall bladder and bile ducts of $N$. meleagris ( $=N$. ptilorhyncha) in Egypt (Lesbouyries 1941) and Lutztrema sp. from the gallbladder of Helmeted guineafowls in Ghana (Hodasi 1976). The former parasite has also been found in the liver of Helmeted guineafowls in the Kruger National Park (Horak 2007, personal communication) and was present in the Musina hosts. The results of this study and unpublished data of Horak (2007) suggest that $D$. macrostomum is not uncommon in South African guineafowls and can reach high intensities in individual hosts.

Postharmostomum gallinum has been reported from the gastro-intestinal tract from Crested guineafowls in Pakistan (Khan, Khan \& Rayaz 1984). Hodasi (1969, 1976) collected Postharmostomum ntowi and Episthmium ghanense and Episthmium africanus from the gastro-intestinal tracts of domestic chickens. Intensities and prevalences were low and the latter author concluded that trematodes were rare parasites in gallinaceous birds.

The fact that the intermediate hosts of trematodes are mainly molluscs or rarely annelids (Gibbons, Jones \& Khalil 1996), both of which are typically associated with moist environmental conditions, might well explain why trematodes played a minor role as parasites of the guineafowls in our dry study area.

\section{Cestodes}

\section{Porogynia}

The presence of young stages of Porogynia paronai in the liver of infected hosts is unusual. Hodasi (1976), however, recovered adult Cotugnia meleagridis from the small intestine of Helmeted guineafowls in Ghana, and recorded numerous young forms of this parasite from the host's gallbladder. Since the life cycle of Porogynia is not known, one can only speculate on the presence of immatures in the liver.

During the normal course of cestode development in avian hosts, the cysticercoid is freed from the arthropod intermediate host in the intestine as a result of mechanical and chemical actions. Subsequently, the scolex evaginates and the cysticercoid attaches itself to the gut wall (Reid 1962). The fact that young $P$. paronai were recovered from the liver of three birds and in relatively high numbers, in addition to 
their uniform stage of development, suggests that their presence is not a result of post-mortem migration. Whether the newly freed cysticercoid, assuming that an arthropod is the intermediate host, migrates up the common bile duct to mature to a certain stage, before leaving the liver to resume its final maturation in the small intestine, or whether we have observed aberrant migration of juvenile stages will remain speculation until the development of $P$. paronai can be studied in more detail.

\section{Abuladzugnia}

Interestingly, the cestode $A$. gutterae, which was common in the guineafowls examined by us was not found in any of the previous surveys. Ortlepp (1963) originally described this species as Cotugnia gutterae from three specimens that had been collected from Crested guineafowls in Mozambique. Since then there seem to have been no further records of this parasite. Spasskii (1973) created the genus Abuladzugnia to accommodate $A$. gutterae and another of Ortlepp's (1963) species formerly described as Cotugnia transvaalensis.

\section{Conclusion}

The above findings suggest, that despite geographical variation in the prevalence and intensity of individual helminth species, probably caused by environmental conditions, such as temperature, rainfall and soil conditions, the helminth community of guineafowls in Africa is composed of a relatively stable body of core and secondary species enriched by satellite species. The latter probably depend on local conditions and can be influenced by abiotic conditions, but also the presence or absence of certain intermediate hosts and other terrestrial birds which may serve as reservoir hosts for certain parasites. We interpret the relative uniformity in the helminth community of Helmeted guineafowls in Africa as flowing from a long host/parasite association during which parasites have spread in conjunction with their hosts.

\section{ACKNOWLEDGEMENTS}

We thank Dr W.J. Luus-Powell, University of Limpopo, who enabled the collection of Helmeted guineafowls in Musina and Mr H.E. Hattingh, University of Limpopo, for collecting and placing the Mokopane material at our disposal as well as for collecting the birds at Musina. Mr K. Meyer and Mr M. Storm kindly made the guineafowls available to us. The techni- cal assistance of Mr. Ryno Watermeyer, University of Pretoria, especially with the processing of the cestodes, is greatly appreciated. This study was made possible by a Claude Leon Foundation Postdoctoral Fellowship grant to the first author.

\section{REFERENCES}

ACOCKS, J.P.H. 1988. Veld types of South Africa, with accompanying veld type map, $3^{\text {rd }}$ ed. (Memoirs of the Botanical Survey of South Africa, no. 57).

ALI, S.M. 1961. On some new nematodes (Habronematinae) from birds in Hyderabad, India, and the relationships of the genus Habronema. Journal of Helminthology, 35:1-48.

ANDERSON, R.C. 1992. Nematode parasites of vertebrates, their development and transmission, $1^{\text {st }} \mathrm{ed}$. Wallingford and New York: CAB International.

CANCRINI, G., BALBO, T. \& IORI, A. 1991. Su un nuovo Habronematidae parassita di Acryllium vulturinum: Sicarius renatae sp. n. Parassitologia (Roma), 33:133-136.

CHABAUD, A.G. 1958. Essai de classification des nematodes Habronematinae. Annales de Parasitologie, 33:445-508.

CHABAUD, A.G. 1975. Keys to genera of the order Spirurida, Part 2. Spiruroidea, Habronematoidea and Acuarioidea, in $\mathrm{ClH}$ keys to the nematode parasites of vertebrates, edited by R.C. Anderson, A.G. Chabaud \& S. Willmott. Farnham Royal: Commonwealth Agricultural Bureaux.

CHABAUD, A.G. \& CAMPANA, Y. 1950. Notes sur le genre Hadjelia Seurat, 1916 (Nématodes-Spiruridae). Annales de Parasitologie Humaine et Comparée, 25:435-440.

CROWE, T.M. 1977. Variation in intestinal helminth infestation of the Helmeted guinea-fowl. South African Journal of Wildlife Research, 7:1-3.

DAVIDSON, W.R., HON, L.T. \& FORRESTER, D.J. 1977. Status of the genus Cyrnea (Nematoda: Spiruroidea) in wild turkeys from the Southeastern United States. Journal of Parasitology, 63:332-336.

DEL HOYO, J., ELLIOT, A. \& SARGATAL, J. (Eds). 1994. Handbook of the birds of the world. Vol. 2, New World vultures to guineafowl. Barcelona: Lynx Edicions.

FABIYI, J.P. 1972. Studies on parasites of the grey-breasted helmet guineafowl (Numida meleagris galeata Pallas) of the Vom area of the Benue Plateau State, Nigeria. I. Helminth parasites. Bulletin of Epizootic Diseases of Africa, 20:235238.

FAIN, A. 1955a. Sur un nouveau Gongyloneme, G. congolense n. sp., parasite de la Poule, du Canard et des Gallinacés sauvages. Revue de Zoologie et de Botanique Africaines, 51:1-10.

FAIN, A. 1955b. Le genre Gongylonema Molin 1857, au Congo Belge et au Ruanda-Urundi. Annales de Parasitologie Humaine et Comparée, 30:202-218.

FAIN, A. \& THIENPONT, D. 1958. Notes sur deux Gongylonèmes congolais parasites de l'Oryctérope et de la Pintade. Revue de Zoologie et de Botanique Africaines, 57:113-116.

GEDOELST, L. 1919. Un genre nouveau de Spiruridae. Comptes Rendus des Séances de la Société de Biologie, 82:11451148.

GIBBONS, L.M., JONES, A. \& KHALIL, L.F. 1996. Eighth international training course on identification of helminth parasites of economic importance. St. Albans: International Institute of Parasitology, Commonwealth Agricultural Bureaux. 
GRABER, M. 1976. Helminthes et helminthiases des animaux domestiques et sauvages d'Ethiopie. Tome 2. Deuxieme Mission des Vétérinaires Français en Ethiopie, Janvier-Mars '75.

HOCKEY, P.A.R., DEAN, W.R.J. \& RYAN, P.G. (Eds). 2005. Roberts-Birds of Southern Africa, VII ${ }^{\text {th }}$ ed. Cape Town: The Trustees of the John Voelcker Bird Book Fund.

HODASI, J.K.M. 1969. Comparative studies on the helminth fauna of native and introduced domestic fowls in Ghana. Journal of Helminthology, 43:35-52.

HODASI, J.K.M. 1976. The helminth parasites of the helmet guinea fowl (Numida meleagris galeata Pallas) in Ghana. Bulletin of Animal Health and Production in Africa, 24:8187.

KHAN, S.W., KHAN, A.J. \& RAYAZ, S. 1984. Helminth parasites found in the gastro-intestinal tract of guinea fowl, Guttera pucherani of Peshawar, N.W.F.P., Pakistan. Bulletin of Zoology, University of Peshawar, 2:57-59.

LEPAGE, D. 2007. Avibase, hosted by Bird Studies Canada, the Canadian copartner of Birdlife International. www.bsc-eoc.org/avibase/avibase.jsp?pg

LE ROUX, P.L. 1926. Helminths collected from the domestic fowl (Gallus domesticus) and the domestic pigeon (Columba livia) in Natal. $11^{\text {th }}$ and $12^{\text {th }}$ Reports of the Director of Veterinary Education and Research, Part 1: 207-217.

LESBOUYRIES, G. 1941. La pathologie des oiseaux. Paris: Vigot Frères.

MAGWISHA, H.B., KASSUKU, A.A., KYVSGAARD, N.C. \& PERMIN, A. 2002. A comparison of the prevalence and burdens of helminth infections in growers and adult free-ranging chickens. Tropical Animal Health and Production, 43:205-214.

MARGOLIS, L., ESCH, G.W., HOLMES, J.C., KURIS, A.M. \& SCHAD, G.A. 1982. The use of ecological terms in parasitology (report of an ad hoc committee of the American Society of Parasitologists). Journal of Parasitology, 56:436-439.

NFOR, M.B., AJANUSI, O.J., AGBEDE, R.I.S. \& ESIEVO, K.A.N. 1999. Prevalence of parasites of guinea fowl (Numida meleagris galeata) in Zaria, Nigeria. Bulletin of Animal Health and Production in Africa, 47:103-106.

NICHOLLS, P.K., BAILEY, T.A., GIBBONS, L.M., JONES, A. \& SAMOUR, J.H. 1995. Parasitic infection in a flock of rufouscrested bustards (Eupodotis ruficrista) in the United Arab Emirates. Journal of Zoo and Wildlife Medicine, 26:590-596.

ORTLEPP, R.J. 1937. South African helminths, Part I. Onderstepoort Journal of Veterinary Science and Animal Industry, 9: 311-336.

ORTLEPP, R.J. 1938a. South African helminths, Part III. Some mammalian and avian cestodes. Onderstepoort Journal of Veterinary Science and Animal Industry, 11:23-50.

ORTLEPP, R.J. 1938b. South African helminths, Part V. Some avian and mammalian helminths. Onderstepoort Journal of Veterinary Science and Animal Industry, 11:63-104.

ORTLEPP, R.J. 1963. Observations on cestode parasites of guinea-fowl from Southern Africa. Onderstepoort Journal of Veterinary Research, 30:95-118.

ORTLEPP, R.J. 1964. Some helminths recovered from Red- and Yellow-billed Hornbills from the Kruger National Park. Onderstepoort Journal of Veterinary Research, 31:39-52.
PERMIN, A., ESMANN, J.B., HOJ, C.H., HOVE, T. \& MUKARATIRWA, S. 2002. Ecto-, endo- and haemoparasites in freeranging chickens in the Goromonzi District in Zimbabwe. Preventive Veterinary Medicine, 54:213-224.

PERMIN, A., MAGWISHA, H., KASSUKU, A.A., NANSEN, P., BISGAARD, M., FRANDSEN, F. \& GIBBONS, L.M. 1997. A cross-sectional study of helminths in rural scavenging poultry in Tanzania in relation to season and climate. Journal of Helminthology, 71:233-240.

POULSEN, J., PERMIN, A., HINDSBO, O., YELIFARI, L., NANSEN, P. \& BLOCH, P. 2000. Prevalence and distribution of gastro-intestinal helminths and haemoparasites in young scavenging chickens in upper eastern region of Ghana, Africa. Preventive Veterinary Medicine, 45:237-245.

QUENTIN, J.C. \& WERTHEIM, G. 1975. Helminthes d'oiseaux et de mammifères d'Israël V. - Spirurides nouveaux ou peu connus. Annales de Parasitologie (Paris), 50:63-85.

REID, W.M. 1962. Chicken and turkey tapeworms. Handbook to aid in the identification and control of tapeworms found in the United States of America. Poultry Department and Poultry Disease Research Center, College Experiment Station, Athens, Georgia.

SAAYMAN, J. 1966. A study of the diet and parasites of Ardeola (Bubulcus) ibis, Numida meleagris and Gallus domesticus from the Eastern Cape Province, South Africa. Ph.D. thesis, University of South Africa.

SCHMIDT, G.D. \& KUNTZ, R.E. 1977. Revision of Mediorhynchus Van Cleave 1916 (Acanthocephala) with a key to species. Journal of Parasitology, 63:500-507.

SEURAT, L.G. 1916. Sur un nouveau type de Spiruridae. Comptes Rendus des Séances de la Societé de Biologie, 79:517519.

SHARMA, R.K. 1971. A new nematode Sicarius hoopoe n. sp. (Habronematinae) from a bird. Zoologischer Anzeiger Leipzig, 187:303-306.

SIEGFRIED, W.R. 1966. Growth, plumage development and moult in the Crowned Guineafowl Numida meleagris coronata Gurney. Department of Nature Conservation Investigational Report No. 8.

SOULSBY, E.J.L. 1968. Helminths, arthropods and protozoa of domesticated animals (Sixth edition of Mönnig's veterinary helminthology and entomology). London: Baillière and Cassell.

SPASSKII, A.A. 1973. [New genera of cyclophyllidean cestodes.] Parazity Zhivotnykh i Rastenii, 9:38-48 [in Russian].

VERCRUYSSE, J., HARRIS, E.A., BRAY, R.A., NAGALO, M., PANGUI, M. \& GIBSON, D.I. 1985. A survey of gastrointestinal helminths of the common helmet guinea fowl (Numida meleagris galeata) in Burkina Faso. Avian Diseases, 29:742745.

VERSTER, A. \& PTASINSKA-KLORYGA, Y. 1987. Helminths of Helmeted guineafowl in southern Africa. South African Journal of Wildlife Research, Supplement I: 36-38.

YAMAGUTI, S. 1961. The nematodes of vertebrates, Vol. III, Part I \& II, in Systema Helminthum. New York: Interscience Publishers. 